\title{
Quantifying the Effects of Hanging Baskets on the Greenhouse Light Environment
}

\author{
James E. Faust ${ }^{1,3}$, Pamela C. Korczynski ${ }^{2}$, and \\ Uttara C. Samarakoon ${ }^{1}$
}

ADDITIONAL INDEX WORDS. container color, container content, container density, daily light integral, photosynthetic photon flux, R:FR

SumMary. During the production of ornamentals in commercial greenhouses, hanging baskets are often grown above the bench or floor space to maximize production. These hanging baskets impact the light environment delivered to the crop underneath. An experiment was conducted to quantify the effect of hanging basket density (determined by number of lines of containers per greenhouse bay and container spacing per line), container content (with plants vs. no plants), and container color (white vs. green) on photosynthetic photon flux $(P P F)$ transmission and red (R) and far-red (FR) light measurements at the greenhouse floor under the hanging basket treatments. Interception of $P P F$ was calculated as a proportion of the treatment with no hanging baskets. Interception of PPF increased as hanging basket density increased, from $5.3 \%$ interception at 0.21 containers $/$ yard $^{2}$ to $25.5 \%$ interception at 2.57 containers $/$ yard $^{2}$. Green containers intercepted $36.1 \%$ more radiation than the white containers. Presence of plants in the containers resulted in 62.3\% greater PPF interception than containers without plants. R:FR was reduced from 1.15 measured under hanging basket treatments without plants to 1.07 under hanging basket treatments containing plants.

$\mathrm{E}$ fficient use of space is critical to the success of commercial greenhouses. Many growers produce hanging basket crops in addition to the crops grown on the bench or floor. In 2012, the wholesale value of flowering hanging baskets in the United States was \$211 million, while foliage hanging baskets were valued at $\$ 78$ million (U.S. Department of Agriculture, 2013). The most popular species grown in hanging baskets were geranium (Pelargonium Xhortorum), impatiens (Impatiens wallerana), new guinea impatiens (Impatiens hawkeri), petunia (Petunia $\times$ bybrida), poinsettia (Euphorbia pulcherrima), and begonia (Begonia xsemperflorens-cultorum).

Concerns exist about the effect of overhead baskets on the light environment delivered to crops grown on benches or floors below hanging baskets; however, quantified data are limited to a recent survey (Llewellyn et al., 2013). The percentage of light reflected or intercepted by the greenhouse glazing and infrastructure alone can range from $30 \%$ to $60 \%$

${ }^{1}$ School of Agricultural, Forest, and Environmental Sciences, Clemson University, Clemson, SC 29634

${ }^{2}$ Department of Ornamental Horticulture and Landscape Design, University of Tennessee, Knoxville, TN 37901

${ }^{3}$ Corresponding author. E-mail: jfaust@clemson.edu. even without hanging baskets (Critten, 1986, 1989, 1993). Hanging baskets potentially impact both the light quantity and spectral light quality delivered to the underlying bench crop as leaves differentially absorb, transmit, or reflect photons (Deregibus, 1985; Holmes and Smith, 1977). $P P F$ interception by hanging baskets will therefore reduce the daily light integral (DLI), delivered to the crop underneath. DLI has a great impact on plant quality because lateral branching and flower number for many species have been found to increase as the DLI increases (Chong et al., 2014; Faust et al., 2005; Holcombe et al., 2001). The presence of hanging baskets can also potentially affect the light quality delivered to the underlying crop by preferentially absorbing $\mathrm{R}(600-$ $700 \mathrm{~nm})$ compared with FR (700$800 \mathrm{~nm}$ ). Red inhibits stem elongation, reduces internode length, and promotes lateral branching (Holmes and Smith, 1977), while FR promotes stem elongation, increases internode length, and reduces lateral branching (Runkle and Heins, 2001; Smith, 1982). Hypothetically, plants grown in hanging baskets will reduce the DLI and the R:FR environment for the crop underneath, thus increasing stem elongation and decreasing crop quality (Pasian, 1994).

A greater understanding of how hanging baskets affect the greenhouse light environment will allow for the optimization of crop production; i.e., maximizing hanging basket production while minimizing the reduction in bench or floor crop quality. Therefore, our objective was to quantify the effect of hanging baskets on the $P P F$ and R:FR transmitted to the greenhouse floor, specifically examining the effects of hanging basket density, the presence of plants in the hanging baskets, and the container color.

\section{Materials and methods}

An experiment was conducted at a commercial greenhouse facility with an aluminum frame gutterconnected greenhouse (X.S. Smith, WA, NC) (lat. $35^{\circ} 32^{\prime} 47.5872^{\prime \prime} \mathrm{N}$, long. $77^{\circ} 3^{\prime} 7.8264^{\prime \prime} \mathrm{W}$, $11 \mathrm{ft}$ elevation), from July through September. Each greenhouse had three individual greenhouse sections, or bays (Fig. 1), which were $21 \times 150 \mathrm{ft}$ with gutters $10 \mathrm{ft}$ and ridges $14 \mathrm{ft}$ tall. The gutters were oriented in a north-south arrangement. The greenhouses were covered with an inflated double-layer polyethylene film and internal and movable 30\% PPFreduction, neutral-density shadecloth (Ludvig Svensson, Charlotte, NC).

An experimental unit consisted of a 63 -ft-diameter circle enclosed by a 10 -ft-tall, 6-mil-thick, black plastic curtain hung from the gutters to the floor around the perimeter of the circle (Fig. 1). The plastic curtain served to eliminate light from outside of the experimental unit reflecting in under the hanging basket treatments. Two experimental units were placed in a three-bay section of a greenhouse. 


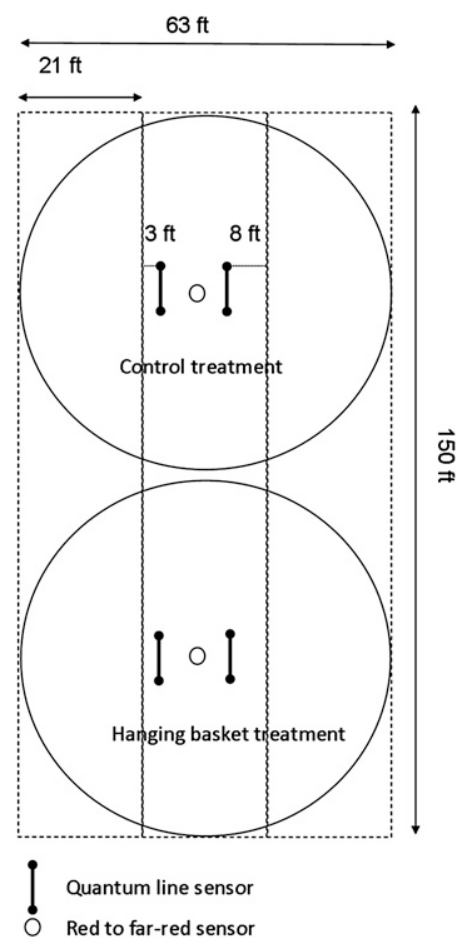

Fig. 1. Schematic diagram of the greenhouse indicating relative location of experimental units and light sensors. The greenhouse consisted of three gutter-connected bays as indicated by the dashed lines. Circles represent the locations of the black plastic sidewalls that defined the perimeter of the experimental treatments; $1 \mathrm{ft}=0.3048 \mathrm{~m}$.

One experimental unit was used for the hanging basket treatments and the other unit served as a control with no baskets overhead.

A quantum sensor (QSO; Apogee Instruments, Logan, UT) was secured outside on the peak of the greenhouse. The greenhouses contained no benches or plants. Two 3.3 - $\mathrm{ft}$ line-quantum sensors ( 20 photodiodes per line, Apogee Instruments) were located $1 \mathrm{ft}$ above the floor, within each of the two experimental units (Fig. 1). Height was determined based on average canopy height of crops grown commonly underneath. The line sensors were placed near the center of the experimental units and either 3 or $8 \mathrm{ft}$ away from the gutter line. An $\mathrm{R}$ to FR sensor (SKR 110; Skye Instruments, Powys, UK) was located in the experimental unit containing the hanging basket treatments between the two quantum line sensors. The $660-730 \mathrm{~nm}$ sensor measures $R$ (610-680 nm with a peak response at $660 \mathrm{~nm}$ ) and FR (690-770 $\mathrm{nm}$ with the peak response at $730 \mathrm{~nm})$. At every 10 min $P P F, \mathrm{R}$ and FR measurements were recorded with an eight-channel quantum integrator (Apogee Instruments). For PPF interception, data were averaged across two sensors and DLI was calculated for each experimental unit. R:FR was calculated using average daily measurements for $\mathrm{R}$ and FR.

As determined by similar DLI, there were no differences in $P P F$ transmission recorded between experimental units before the commencement of the experiment; i.e., before hanging baskets were positioned overhead. Percentage of PPF interception for each treatment was calculated as the difference between the DLI measured under the hanging basket treatment in the first experimental unit and the DLI measured in the second experimental unit containing no hanging baskets. Thus, PPF interception reflects the effect of hanging baskets alone and these measurements do not take into account the effect of $P P F$ transmission through the greenhouse structure.

Hanging baskets of 10 -inch diameter were hung on lines running parallel to the gutters, which were at the same height as the gutter $(10 \mathrm{ft})$. The lines were located $0,3,6$, and $10.5 \mathrm{ft}$ from each gutter in each direction. The line located at $0 \mathrm{ft}$ was hung directly under the gutter, while the line located $10.5 \mathrm{ft}$ from the gutter was the centerline of each bay; i.e., positioned directly under the peak. The containers measured 18 inches from the container base to the top of the hanger.

HANGING BasKet Density. Five hanging basket density treatments at $0.21,0.43,0.64,1.29$, or 2.57 containers/yard ${ }^{2}$ were provided by altering the number of overhead hanging basket lines per bay and the container spacing per line. Three line densities were provided, e.g., one, three, and six lines per bay. The single-line treatment consisted of the centerline in each bay positioned $10.5 \mathrm{ft}$ from both gutters. The three-line treatment consisted of the centerline and the two lines located $3 \mathrm{ft}$ from each gutter in each bay. The six-line treatment consisted of the two lines located 3 and $6 \mathrm{ft}$ from each gutter, the centerline and the lines under each gutter. Thus, there were five lines in the bay and one line under each gutter. Since neighboring bays share the gutter line, this treatment was considered to have six lines per bay.

Container spacing was defined as the distance between the centers of the baskets hanging on the same line. The linear spacing was either 12 or 24 inches. Spacing to the sides of the containers depended on the line density treatment. Containers in the 12 -inch spacing treatment were hung in a staggered formation; i.e., alternating baskets along the line were hung from 18 -inch S-hooks. As the containers measured 18 inches, the container base for the top line of baskets was positioned $8.5 \mathrm{ft}$ above the floor and $7.5 \mathrm{ft}$ above the sensors, while the lower baskets were positioned $7 \mathrm{ft}$ above the floor and $6 \mathrm{ft}$ above the sensors. Containers in the 24-inch spacing treatment were hung as a single line at the same height as the topline of 12 -inch spacing treatment. The number of hanging baskets placed in the experimental unit ranged from 97 used in the single-line per bay $\left(0.21\right.$ containers $/$ yard $\left.^{2}\right)$ and 24-inch spacing treatments to 1164 baskets $\left(2.57\right.$ containers $/$ yard $\left.^{2}\right)$ used in the six-lines per bay and 12 -inch spacing treatments.

Container color. Comparisons were made between 10-inch-diameter green containers (ITML, Brantford, ON, Canada) and 10-inch-diameter white containers (Dillen Plastics, Middlefield, $\mathrm{OH}$ ) of similar height (6.7 inches) and shape.

Container content. Empty containers were compared with containers filled with media and an established plant. The plants were multistem 'Freedom Red' poinsettia measuring 18 inches tall from the container base and 14 inches wide. The plants were trimmed between treatments so that plant growth during the experiment did not impact the irradiance measurements.

EXPERIMENTAL DESIGN AND DATA ANALYSIS. The treatments consisted of five hanging basket densities, two container colors, and two container content treatments arranged in a factorial design. Twenty hanging basket treatments were hung $3 \mathrm{~d}$ per treatment, thus repeated measurements were replicates. Data were analyzed using the General Linear Models procedure of SAS (version 8; SAS Institute, Cary, NC). An arcsin transformation 
was used to perform statistical analysis on the percentage of PPF transmission.

\section{Results}

PPF Interception. The greenhouse structures without any hanging basket treatments (control) intercepted $48 \%$ of the outside PPF. The average DLI measured outdoors during the experiment was $38.6 \mathrm{~mol} \cdot \mathrm{m}^{-2} \cdot \mathrm{d}^{-1}$, so the control greenhouse averaged $20.1 \mathrm{~mol} \cdot \mathrm{m}^{-2} \cdot \mathrm{d}^{-1}$ at the floor.

PPF interception by the hanging basket was influenced by container density, color, and contents (Table 1, Fig. 2) and as described above, it was interpreted as a percentage to the control. PPFinterception increased as hanging basket density increased (Fig. $2)$. For example, average $P P F$ interception across container content and container color treatments increased from $5.3 \%$ at 0.21 containers $/$ yard $^{2}$ to $25.5 \%$ at 2.57 containers/yard ${ }^{2}$. Across hanging basket density and container content, green containers increased average PPF interception by $36.1 \%$ compared with the white containers. The treatments without plants averaged $4.9 \% P P F$ interception for the white container treatments compared with $9.8 \%$ for the green container treatments. The white container treatments with plants averaged 15.1\% PPF interception, while the green container treatments with plants averaged $22.3 \%$.

Container content had a significant effect on PPF transmission (Table 1). Treatments with plants in the containers averaged a $62.3 \%$ increase in PPF interception compared with the same treatments without plants (Fig. 1). The greatest PPF interception percentage for a specific treatment was $44.7 \%$, which occurred when the green containers with plants were placed at the highest hanging basket density (2.57 containers/ $\left.\operatorname{yard}^{2}\right)$.

SPeCTRAL QUALITY. Container content was the only treatment that significantly affected R:FR (Table 1). The presence of plants in the containers decreased the R:FR from 1.15 to 1.08 across all treatments (Fig. 3). The lowest R:FR recorded was 1.04, which occurred with plants in green containers placed at the highest hanging basket density (2.57 containers/ yard $\left.{ }^{2}\right)$. Hanging basket density or container color did not affect R:FR.

\section{Discussion}

The goal for the commercial grower is to determine the proper balance between maximizing the number of hanging baskets grown while continuing to produce commercially acceptable bench or floor crops. Since hanging baskets in a greenhouse will intercept sunlight that would have illuminated the greenhouse bench or floor, each container hung overhead results in an additional reduction in the DLI delivered to the bench or floor crop. As evident during this study, the hanging basket density, plant size, and container color are factors that impact the $P P F$ delivered to the underlying greenhouse crop and must be considered when determining the number and type of hanging baskets to hang in the greenhouse.

One approach to optimizing hanging basket production while continuing to produce a high quality bench crop is to monitor the DLI with a weather station and to estimate the greenhouse $P P F$ transmission percentage by comparing measurements made outside and inside the greenhouse with a portable sensor. By making an assumption about the DLI required to produce the bench crop, one can estimate whether the number of hanging baskets should be decreased or could be increased. For example, the quality of many greenhouse ornamental crops is commercially acceptable when the plants receive a DLI of $10 \mathrm{~mol} \cdot \mathrm{m}^{-2} \cdot \mathrm{d}^{-1}$ (Holcombe et al., 2001). Therefore, the goal would be to identify hanging basket arrangements that allow $10 \mathrm{~mol} \cdot \mathrm{m}^{-2} \cdot \mathrm{d}^{-1}$, on average, to be transmitted to the bench crops. For example, a greenhouse in Columbia, MO, would receive an average of $8,11,14,19,21$, and 24 $\mathrm{mol} \cdot \mathrm{m}^{-2} \cdot \mathrm{d}^{-1}$ from January through June, respectively (Renewable Resource Data Center, 2001), assuming 50\% greenhouse light transmission without any hanging baskets. Thus, no hanging baskets would be placed overhead during January, since the bench crop would receive less than $10 \mathrm{~mol} \cdot \mathrm{m}^{-2} \cdot \mathrm{d}^{-1}$ without any baskets. Hanging baskets could intercept $9 \%, 29 \%, 47 \%, 52 \%$, and $58 \%$ of the PPF delivered during February through June, respectively, while allowing $10 \mathrm{~mol} \cdot \mathrm{m}^{-2} \cdot \mathrm{d}^{-1}$, on average, to continue to be transmitted to the bench crop. Hanging basket density could be altered by changing the number of overhead hanging basket lines per bay and the container spacing per line, as suggested in this study. For example, assuming that in January through March the plants would be quite small, and in April through June the plants were relatively large, we can use the data in Fig. 2 to estimate the maximum number of hanging baskets that could be grown in green containers for each month. No hanging baskets would be recommended for January and 0.8 containers $/$ yard $^{2}$ could be grown in February. At least 2.6 containers/yard ${ }^{2}$ could be grown in March and April.

Table 1. The analysis of variance table for the effects of hanging basket density (containers/yard ${ }^{2}$ ), container color (green or white), and container content (plant or no plant) on photosynthetic photon flux $(P P F)$ interception and red to far-red light ratio ( $R: F R)(n=3)$.

\begin{tabular}{|c|c|c|c|c|}
\hline \multirow[b]{2}{*}{ Source } & \multicolumn{2}{|c|}{$P P F$ interception } & \multicolumn{2}{|c|}{ R:FR } \\
\hline & F value & Significance & F value & Significance \\
\hline Hanging basket density & 71.8 & $* * *$ & 0.5 & NS \\
\hline Container content & 253.1 & $* * *$ & 90.3 & $* * *$ \\
\hline Hanging basket density $\times$ container color & 4.2 & ** & 0.4 & NS \\
\hline Hanging basket density $\times$ container content & 5.6 & ** & 1.0 & NS \\
\hline
\end{tabular}

NS, ${ }^{* *},{ }^{* *}$ Nonsignificant or significant at $P \leq 0.01$ or 0.001 , respectively. 


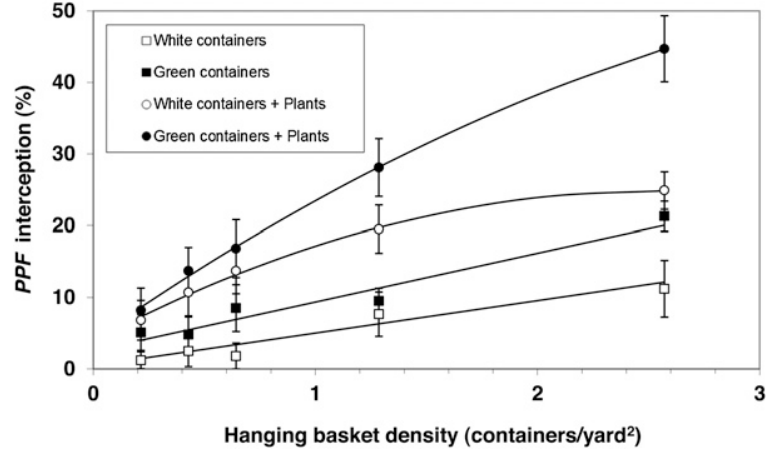

Fig. 2. Effect of hanging basket density, container color (green or white), and container content (plant or no plant) on photosynthetic photon flux (PPF) interception recorded $1 \mathrm{ft}(30.5 \mathrm{~cm})$ above the greenhouse floor. Percentage of PPF interception compares measurements made under the hanging basket treatments to the control (an adjacent experimental unit in the same greenhouse with no hanging baskets). Regression equations are: white containers $(0.47+$ $4.54 X\left(R^{2}=0.85\right)$; green containers, $2.55+6.80 X\left(R^{2}=0.97\right)$; white containers with plants, $3.93+16.4 \mathrm{X}-3.23 \mathrm{X}^{2}\left(\mathrm{R}^{2}=0.91\right)$; green containers with plants, $4.09+21.6 \mathrm{X}-2.28 \mathrm{X}^{2}\left(\mathrm{R}^{2}=0.99\right)$. Error bars indicate \pm 1 SE $(n=3)$;

1 container $/$ yard $^{2}=1.1960$ container $/ \mathrm{m}^{2}$.

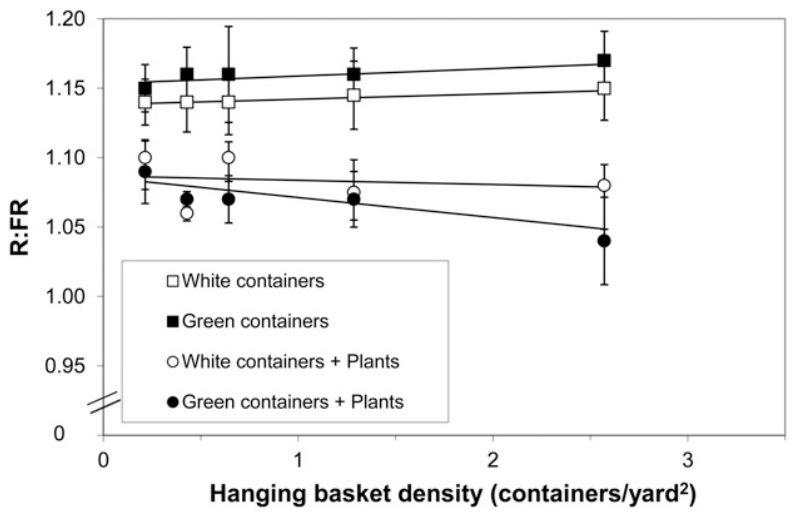

Fig. 3. Effect of hanging basket density, container color (green or white), and container content (plant or no plant) on the red to far-red light ratio (R:FR) measured $1 \mathrm{ft}(0.305 \mathrm{~m})$ ) above the greenhouse floor. Error bars indicate $\pm 1 \mathrm{SE}$ $(\mathbf{n}=3) ; 1$ container $/$ yard $^{2}=1.1960$ container $/ \mathrm{m}^{2}$.

Assuming that an additional $40 \% P P F-$ reduction shade curtain would be added to the greenhouse for May and June to help with heat control, then 0.8 and 1.4 containers/yard ${ }^{2}$ could be grown during those two months, respectively. This example underscores the challenge of matching production demands with the monthly changes in the PPF environment.

Hanging basket line orientation and height above the bench crop could also impact $P P F$ uniformity on the greenhouse floor or bench. In this study, the hanging basket lines were north-south oriented, which allows for relatively uniform shadow distribution during the course of a day as the sun moves from east to west. However, east-west oriented lines would result in a more constant shadow pattern and poorer PPF uniformity, especially during the winter months when the solar elevation angle is low. The baskets in this study were hung from lines 10 or $8.5 \mathrm{ft}$ above the ground. The closer the baskets are to the bench crop, the darker the shadow cast by the basket and the slower that shadow moves across the underlying crops. Therefore, higher basket lines and northsouth line orientation are suggested for improved $P P F$ uniformity. However, on average, a basket will intercept similar PPF levels regardless of the orientation of the line or height above the bench. Thus, line orientation and height should not impact the total number of photons intercepted, only the uniformity of their distribution.

Container color is predominately dictated by the market; however, if the grower has flexibility in determining the container color, it would be advantageous to hang white containers overhead during months with low DLIs. Our data suggest that using white containers would allow growers to place up to $36 \%$ more hanging baskets overhead than green hanging baskets while maintaining a similar $P P F$ interception.

Comparison between containers with and without plants also emphasizes the importance of plant size when considering PPF interception by hanging baskets. There is considerable variation in the desirable market size for different species. For example, fuchsia (Fuchsia $\times$ hybrida) and boston fern (Nephrolepis exaltata) baskets may be 2 to $3 \mathrm{ft}$ diameter, while a geranium basket may be marketable at 12 to 14 inches diameter. Although interception in white containers with plants was less even at high hanging-basket densities (Fig. 2), we expect that plants with a trailing habit would negate some of the benefit of using white containers because less radiation would reflect off the side and bottom of the container.

Plants in the hanging baskets reduced the R:FR delivered to the bench crop. Although requirements of R:FR for bench crops are not well documented, the magnitude of the change in R:FR recorded (Fig. 3) is not likely to have a large impact on bench crop growth. At the current density range, unfiltered sunlight delivered between the hanging basket lines delivers a large number of $\mathrm{R}$ and FR photons in a balanced ratio in comparison with the low number of photons being transmitted through or reflected off the canopy. Therefore, the number of direct sunlight photons in a balanced R:FR overrides the small number of photons delivered in a low R:FR. Thus, R:FR measured at the bench would only be greatly affected by plants in the hanging basket canopy when the plants covered a large portion of the "sky," effectively increasing the amount of 
filtered light relative to unfiltered light. If this situation existed, we would expect a significant increase in stem elongation (Rajapakse and Kelly, 1992; Runkle and Heins, 2001) due to the low R:FR, but the DLI delivered may likely be insufficient for normal plant growth and development.

In summary, our data suggest that the primary effect that hanging baskets have on the greenhouse light environment is the reduction of the DLI transmitted to the bench crop, and this varies with hanging basket density, color of the container, and plant size. The effect of hanging baskets on DLI will limit the growth of the underlying crops before the R:FR environment becomes limiting for plant growth.

\section{Literature cited}

Chong, J.A., U.C. Samarakoon, and J.E. Faust. 2014. Effects of daily light integral and canopy density on shoot growth and development in a poinsettia (Euphorbia pulcherrima Willd. ex. Klotsch) stock plant canopy. HortScience 49:5l-54.

Critten, D.L. 1986. A general analysis of light transmission in greenhouses. J. Agr. Eng. Res. 33:289-302.
Critten, D.L. 1989. Light transmission into greenhouses: Energy saving in protected cultivation. Acta Hort. 245:377383 .

Critten, D.L. 1993. A review of the light transmission into greenhouse crops: Greenhouse crop models. Acta Hort. 328:9-31.

Deregibus, V.A. 1985. Tillering responses to enrichment of red light beneath the canopy in a humid natural grassland. J. Appl. Ecol. 22:199-206.

Faust, J.E., V. Holcombe, N.C. Rajapakse, and D.R. Layne. 2005. The effect of daily light integral on bedding plant growth and flowering. HortScience 40:645649.

Holcombe, M.G., B. Veronda, K. Lewis, and J.E. Faust. 2001. How much light do bedding plants really need? Greenhouse Product News 11(7):26-30.

Holmes, M.G. and H. Smith. 1977. The function of phytochrome in the natural environment. II: The influence of vegetation canopies on the spectral energy distribution of natural daylight. Photochem. Photobiol. 25:539-545.

Llewellyn, D., Y. Zheng, and M. Dixon. 2013. Survey of how hanging baskets influence the light environment at lower crop level in ornamental greenhouses in
Ontario, Canada. HortTechnology 23: 823-829.

Pasian, C. 1994. Growing environment, p. 9-11. In: M.L. Gaston, P.S. Konjoian, S.A. Carver, C.A. Buck, and R.A. Larson (eds.). Tips on growing and marketing hanging baskets. Ohio Florists. Assn., Columbus, $\mathrm{OH}$.

Rajapakse, N.C. and J.W. Kelly. 1992. Regulation of chrysanthemum growth by spectral filters. J. Amer. Soc. Hort. Sci. 117:481-485.

Renewable Resource Data Center. 2001. Solar radiation resource information. Daily statistics files. The national solar radiation data base. 10 Jan. 2001. $<$ http://www.nrel.gov/rredc/solar_ resource.html>.

Runkle, E.S. and R.D. Heins. 2001. Specific functions of red, far red, and blue light in flowering and stem extension of long-day plants. J. Amer. Soc. Hort. Sci. 126:275-282.

Smith, H. 1982. Light quality, photoperception, and plant strategy. Annu. Rev. Plant Physiol. 33:481-518.

U.S. Department of Agriculture. 2013. Floriculture crops 2012 summary. 11 Nov. 2013. <http://www.nass.usda. gov/Publications/Todays_Reports/ reports/floran 13.pdf $>$. 